\title{
Rapid glacier sliding, reverse ice motion and subglacial water pressure during an autumn rainstorm
}

\author{
T.J. FUDGE, ${ }^{1}$ J.T. HARPER, ${ }^{2}$ N.F. HUMPHREY, ${ }^{3}$ W.T. PFEFFER ${ }^{4}$ \\ ${ }^{1}$ Department of Earth and Space Sciences, University of Washington, Box 351310, Seattle, WA 98195-1310, USA \\ E-mail: tjfudge@u.washington.edu \\ ${ }^{2}$ Department of Geosciences, University of Montana, Missoula, MT 59812-1296, USA \\ ${ }^{3}$ Department of Geology and Geophysics, University of Wyoming, Laramie, WY 82071-3006, USA \\ ${ }^{4}$ Institute of Arctic and Alpine Research, University of Colorado, Boulder, CO 80309-0450, USA
}

\begin{abstract}
Measurements of basal water pressure from 15 boreholes located at both local (tens of meters) and regional (kilometers) length scales were used to elucidate the pressure/sliding relationship during an autumn rapid motion event on Bench Glacier, Alaska, USA. The 8 day event had two distinct phases, each with a ten-fold speed-up with respect to winter velocity. The water pressure in all $\mathbf{1 5}$ boreholes varied synchronously during the speed-up. The first phase of rapid sliding began after a peak in basal water pressure and continued while the pressure was elevated and stable, or decreasing. The second phase of rapid sliding occurred when the basal water pressure was low but increasing, and terminated before the pressure peaked. Pressure and velocity do not appear unrelated, but the pressure/sliding relationship was not consistently linked to increasing, decreasing or a critical water pressure. The pressure variations and sliding accelerations are a response to a warm rainstorm, although equally large input events occurred in weeks prior with no apparent response. Drainage system evolution therefore appears to play a key role in both the acceleration and the pressure/velocity relationship. Basal cavity dynamics are likely responsible for three episodes of reverse (up-valley) motion observed after enhanced sliding.
\end{abstract}

\section{INTRODUCTION}

Enhanced sliding due to seasonal water input is a longestablished component of glacier motion (e.g. Willis, 1995) and has recently been documented in ice sheets (Zwally and others, 2002; Joughin and others, 2008). However, the physical processes that govern the role of water in sliding remain poorly understood (Fountain and Walder, 1998; Hooke, 1998). Despite the key role of water in basal processes, rapid sliding events do not necessarily coincide with times of maximum water input (Truffer and others, 2005). Instead, rapid sliding events often occur after large increases in the rate of water input, such as in the spring (e.g. Mair and others, 2001; Harper and others, 2007), during rain events (e.g. O'Neel and others, 2001) and during outburst floods (e.g. Magnússon and others, 2007). The 'antecedent conditions' of the basal drainage therefore appear crucial to predicting sliding accelerations.

Sliding models often treat basal water pressure as the key water parameter dictating sliding (Lliboutry, 1968; Röthlisberger; 1972, Fowler, 1987; Schoof, 2005). Indeed, some observational experiments have determined that basal water pressure correlates well with sliding (Jansson, 1995); other studies, however, have found poor correlations (e.g. Iken and Truffer, 1997; Hanson and others, 1998), and in some cases sliding has been related to water storage (Kamb and others, 1994; Meier and others, 1994). Discerning the relationship between sliding speed and water pressure is hampered by the difficulty of measuring basal pressure. Pressure is typically measured in a small number of spatially limited boreholes, or is sometimes inferred from records of surface uplift by assuming uplift results from a pressure increase (Zwally and others, 2002).

Here we present detailed records of water pressure during a week-long autumn rapid-motion event on Bench Glacier, Alaska, USA. The subglacial water-pressure field is calculated from an array of 15 boreholes and considers both the local (tens of meters) and regional (kilometers) length scales. We find no consistent relationship between glacier motion and basal pressure at either length scale, suggesting that more complex basal processes govern the sliding accelerations.

\section{DATA COLLECTION}

\section{Bench Glacier}

Field observations were made at Bench Glacier, a temperate glacier located in the Chugach mountain range of southcentral Alaska. The $7 \mathrm{~km}$ glacier terminates at $1100 \mathrm{~m}$ elevation, and has an equilibrium-line altitude of about $1400 \mathrm{~m}$ (Fig. 1). Bench Glacier has a relatively simple geometry with no major tributaries. The average surface slope is about $10^{\circ}$, with one steeper section just above the equilibrium line sloping 20-30 . Radar profiles of the bed show a parabolic cross-section without major riegels and that the bed has an average slope in the ablation area of $3.5^{\circ}$ (Bradford and Harper, 2005). The ice depth increases upglacier throughout the ablation area to a maximum of about $200 \mathrm{~m}$ near the equilibrium line. Borehole video inspection, penetrometer tests and careful monitoring of the drill tip as it encountered the bed showed only rare patches of till, so we classify the bed as 'hard'. One major stream exits the glacier at the terminus, with average streamflow during the summer of about $5 \mathrm{~m}^{3} \mathrm{~s}^{-1}$ (Anderson and others, 2004) and at least an order of magnitude less in the winter.

\section{Borehole water levels}

A total of 43 boreholes were drilled to the bed (140-190 m) and instrumented during spring of 2002 and 2003. The boreholes were drilled using hot-water methods during May and early June when the glacier was snow-covered. We 


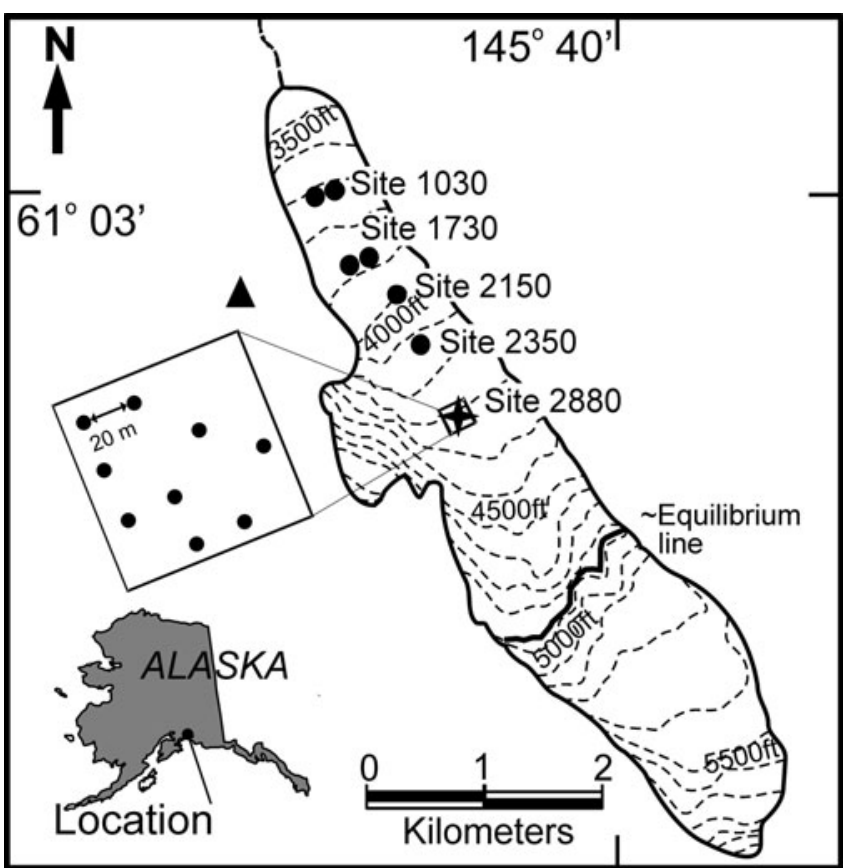

Fig. 1. Map of Bench Glacier and measurement locations. Circles show boreholes; the star shows the GPS 'rover' receiver; the triangle indicates the position of the meteorological station and GPS 'base' receiver; the solid line indicates the approximate equilibrium line; dashed lines indicate elevation contours of $100 \mathrm{ft}(\sim 30.5 \mathrm{~m})$. Borehole sites are named by the distance, in meters, from the terminus. Regional water pressure is averaged from measurements at the five sites; local water pressure is averaged from measurements in the nine boreholes at site 2880 .

assume the boreholes to be nearly vertical based on detailed inclinometry measurements of boreholes drilled using the same equipment and procedures (Harper and others, 2001). On intersection with the bed, the drill was reversed and readvanced repeatedly in an effort to penetrate possible englacial debris near the bed.

Boreholes were spaced as pairs $20 \mathrm{~m}$ apart at different sites spanning the entire length of the glacier, and one 16borehole grid in the center of the ablation area. Sites are named as the distance (in meters) up-glacier from the terminus. In the autumn of 2003, pressure sensors in 15 boreholes remained operational, four from 2002 and 11 from 2003 (Fig. 1). The boreholes from 2003 were open at the surface, whereas the tops of the boreholes from 2002 had been frozen shut during the previous winter. No sensors were operational in boreholes located above site 2880 .

A pressure transducer was lowered to within $1 \mathrm{~m}$ of the bed in each borehole and connected to a data logger at the surface. The resolution of water-level differences between boreholes is $\sim 2 \mathrm{~m}$; this results mostly from errors derived from surface lowering by ablation, although we fixed cables at the surface to minimize this effect. The data loggers recorded measurements every 15 min during the autumn season.

\section{Ice motion}

Glacier motion was recorded with two Trimble Geomatic R5700 global positioning system (GPS) receivers logging at $30 \mathrm{~s}$ intervals and installed as a 'rover' and 'base'. The rover was installed in the center of site 2880 with piers drilled into the ice, and the base station was placed on rock on a ridge adjacent to the glacier. The receivers were operational throughout the summer and were reset between days 246 and 248. The base station malfunctioned on day 250 , whereas the rover operated until day 328. Two processing techniques (described below) were used: (1) Trimble Geomatics Office for the full record (Fig. 2); and (2) Precise Point Positioning (PPP) for more precise locations during the autumn speed-up (Figs 3 and 4).

The failure of the local base station required the use of two more distant but continuously operating base stations, Potato Point (55 km east) and Cape Hinchinbrook (103 km south-southeast), for processing with Trimble Geomatics Office. The GPS records were processed into 12 hour positions for the full length of the record. Errors were large because of the long baselines between the rover at site 2880 and the base stations; the horizontal and vertical errors were typically 10 and $20 \mathrm{~cm}$, respectively.

The PPP system available through the Canadian Natural Resources Department was used to achieve more precise positions for data covering the autumn speed-up (Heroux and Kouba, 2001), days 269-278. It is these more precise data that will be compared in detail with the water-level records during the speed-up. PPP processing uses corrected satellite orbits and does not require a fixed reference station. Static 4 hour positions were calculated, as this was the minimum time resolution with acceptable positional errors. The mean, two-sigma errors for latitude, longitude and elevation are $3.9 \mathrm{~cm}, 7.3 \mathrm{~cm}$ and $14.5 \mathrm{~cm}$, respectively. To check for biasing errors that might be introduced by processing a moving glacier in static mode (King, 2004), we also processed using kinematic methods with the PPP software and did not find any consistent biasing in the static positions.

\section{Meteorological data}

A meteorological station was installed on a ridge adjacent to Bench Glacier (Fig. 1); it recorded temperature, rainfall, solar radiation, wind speed and wind direction in 4 hour averages from May to December, 2003. The ridge site is higher than the immediately adjacent glacier surface but roughly equal in elevation to site 2880 . The main difference between the ridge and the glacier is the lack of katabatic winds at the ridge during warm, clear-sky days. A pressure transducer was placed in the outlet stream at the end of summer but was not recovered the following spring; therefore we do not have streamflow estimates during the autumn.

\section{RESULTS}

Records from the period mid-July to mid-November reveal a distinct seasonal evolution of borehole water-level patterns and glacier motion in addition to several significant meteorological events (Fig. 2). The week-long autumn speed-up (days 270-278) clearly stands out within the records as an unusual event. The horizontal motion in Figures $2 \mathrm{a}, 3 \mathrm{a}$ and $4 \mathrm{a}$ is plotted as the distance along the vector of the main direction of flow. This vector is the best-fit normal line to the positions. A velocity time series was not computed due to errors of the individual positions and the noise associated with differentiating digital data. Two length scales of the average borehole water level are shown in Figures $2 \mathrm{~b}$ and $3 \mathrm{~b}$. The local water level is the average of the nine boreholes at site 2880 (Fig. 1). The regional water level is the average of the mean water level at each of the five sites. 


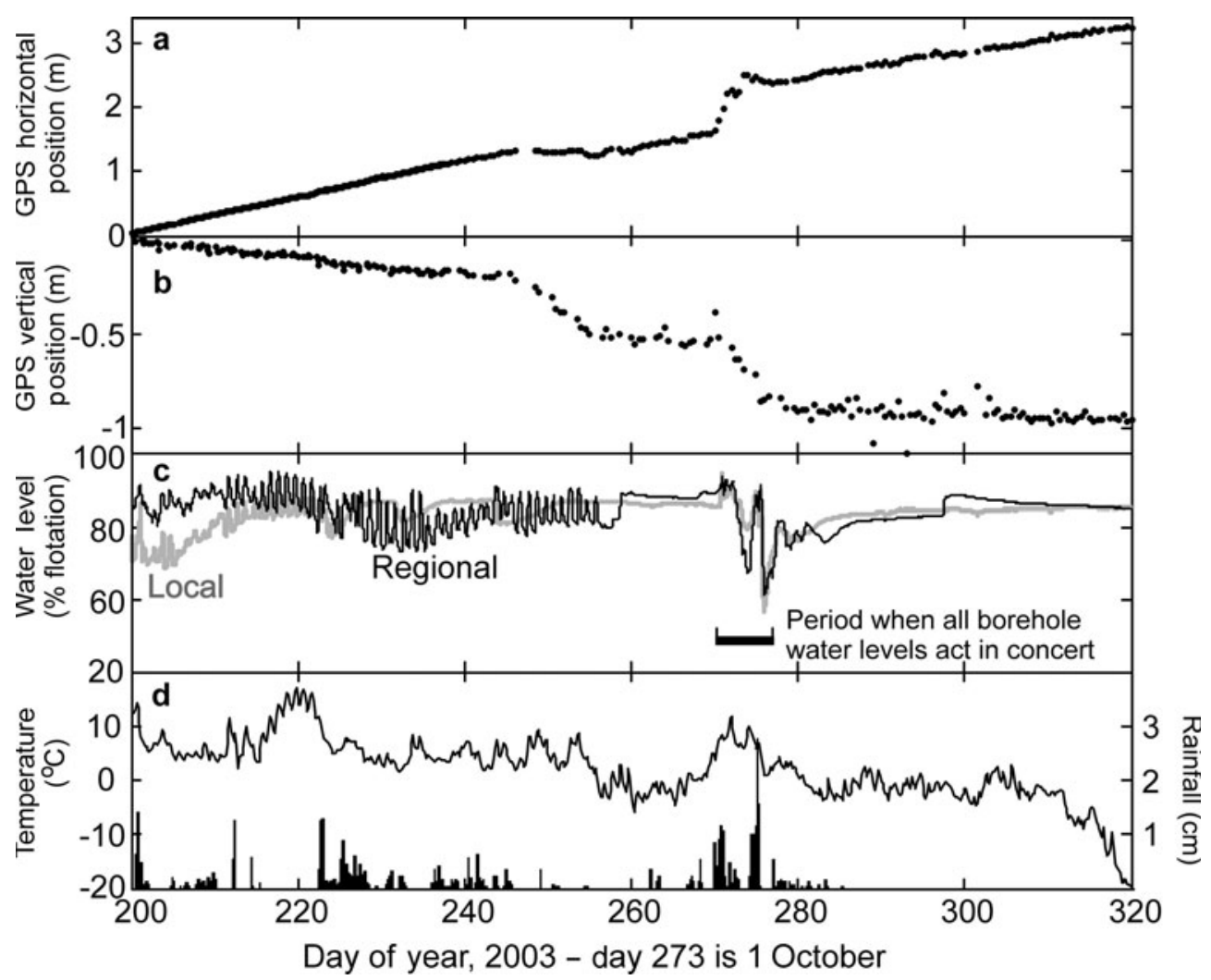

Fig. 2. Data spanning the summer to winter transition. (a) Horizontal surface motion recorded by GPS at site 2880; (b) vertical surface motion recorded by GPS at site 2880; (c) local (thick curve) and regional (thin curve) average water level (see Fig. 1 caption); (d) temperature and rainfall. GPS positions processed with Trimble Geomatics Office; horizontal $(\sim 10 \mathrm{~cm})$ and vertical $(\sim 20 \mathrm{~cm})$ errors are not shown. The speed-up event (days 270-278) clearly stands out in all records. Prior to the speed-up (days 248-270), the horizontal velocity slowed and the surface elevation had downward motion. High temperatures and significant rain earlier in the year (days 217-227) failed to produce a similar speed-up. The average water levels are only considered representative of the average basal pressure from days 270-276 (see Fig. 5).

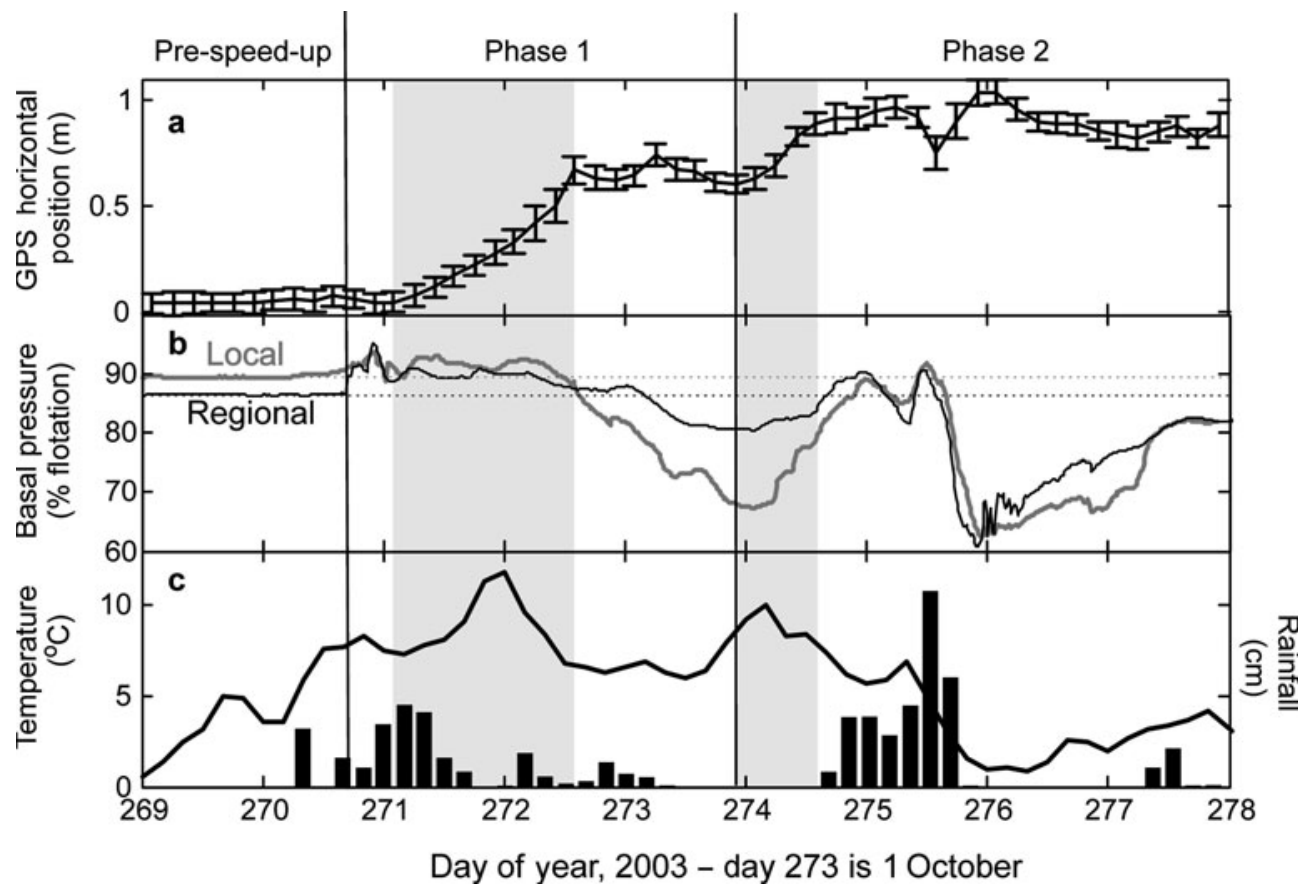

Fig. 3. Autumn speed-up event. (a) Horizontal surface motion recorded by GPS at site 2880; error bars represent $95 \%$ confidence interval; (b) local (solid curve) and regional (dashed curve) water pressure; horizontal dotted lines are pre-event pressure; (c) temperature and rainfall. GPS positions processed using PPP. The speed-up is divided into two phases. During phase I, rapid sliding occurred for $\sim 36$ hours (first shaded box) during elevated pressure and after a pressure spike. During phase II, rapid sliding occurred for $\sim 16$ hours (second shaded box) while the pressure was increasing. Velocity slowed during phase II before pressure reached a maximum. 


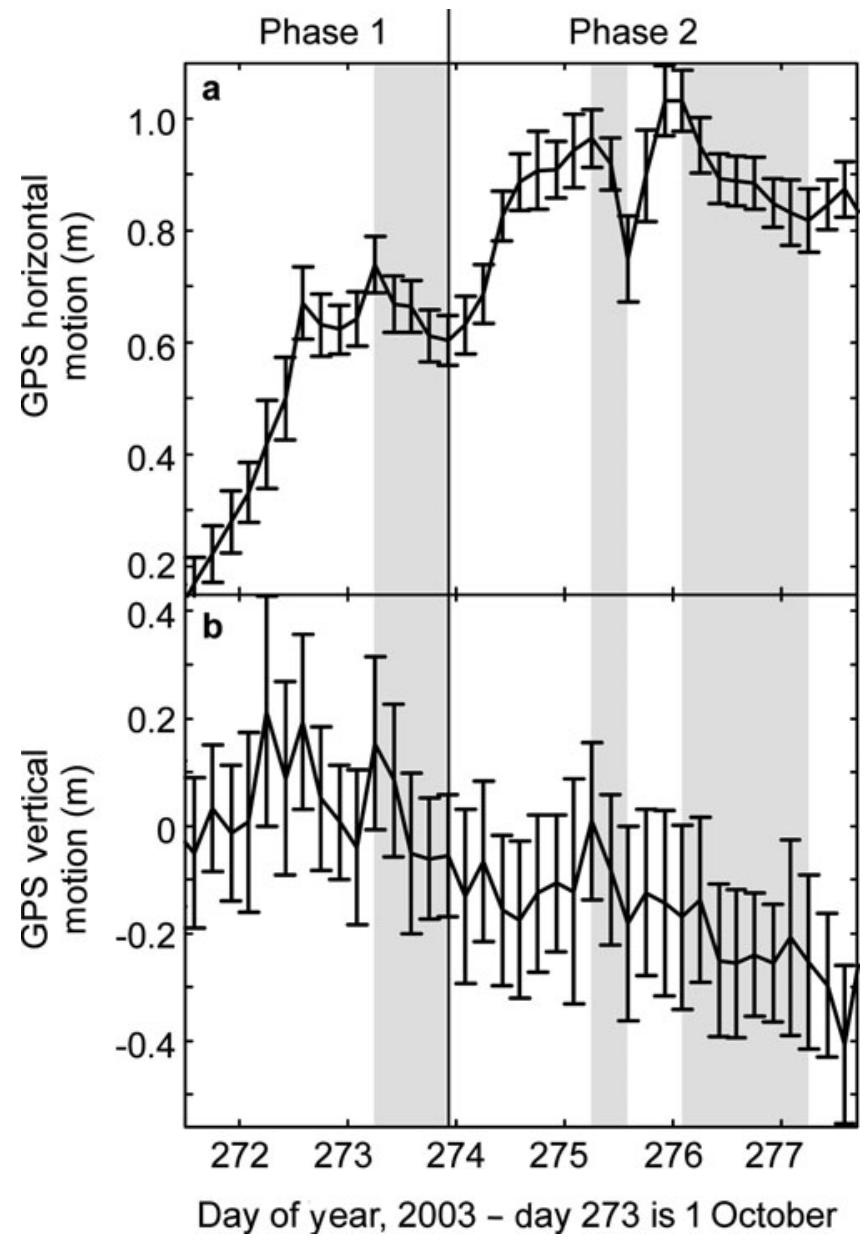

Fig. 4. Reverse-motion events. Horizontal motion (a) and vertical motion (b) recorded by GPS at site 2880 processed with PPP. Error bars represent $95 \%$ confidence interval $(\mathrm{Cl})$. Shading shows times of reverse motion. The amount of reverse motion was $15 \mathrm{~cm}(4-26 \mathrm{~cm}$, when considering $95 \% \mathrm{Cl})$ at the end of phase I, $21 \mathrm{~cm}(8-34 \mathrm{~cm})$ during phase II, and $21 \mathrm{~cm}(11-31 \mathrm{~cm})$ at the end of phase II. Vertical motion cannot be determined for individual episodes because of the large errors. The total downward surface motion from days $272-277$ was $62 \mathrm{~cm}(26-98 \mathrm{~cm})$.

To understand this event within the framework of seasonal changes, we first investigate when the average borehole water level can be considered representative of a basal water pressure. We then examine the glacier motion, basal pressure and meteorological data in more detail during the pre-speed-up, speed-up and post-speed-up periods.

\section{Basal water pressure}

Determining basal water pressure from borehole water-level measurements is not straightforward. First, the boreholes act as manometers only if the volume of water at the bed is large in comparison with the borehole and any water flow through the borehole does not significantly affect the subglacial hydrology system (e.g. Harper and others, 2002). Second, the water level in an individual borehole might not be representative of average basal conditions (e.g. Fountain, 1994; Gordon and others, 1998; Fudge and others, 2008). For studies examining the relationship of basal water pressure and sliding, the relevant length scale for basal pressure is not known but has been suggested to be one to a few ice thicknesses based on the longitudinal stress-coupling lengths (e.g. Anderson and others, 2004; Howat and others,
2008). Therefore, a reliable estimate of average basal water pressure can be achieved only when many borehole waterlevel records over a large area show similar fluctuations.

The water levels of four different boreholes are shown in Figure 5. Two of the records are from site 2880 (16-borehole grid), whereas the other two are from sites 1730 and 1060 . Any of the 15 boreholes could have been chosen, as all show a similar pattern (in fact, these four were chosen because they did not overlap extensively and could be discerned in the figure). Before the autumn speed-up, boreholes reached a stable water level, with diurnal fluctuations in water level lasting as late as day 260 in a couple of boreholes. During the speed-up, the water levels in all 15 boreholes follow the same basic pattern: a sudden increase and sustained high levels (270-272), a broad decline before a double-humped peak (272-275), and a final decline (275-276). On day 276, the borehole water levels no longer vary in unison as the water levels return irregularly to the high, stable levels typical of winter (Fudge and others, 2005) over a period of days to weeks.

All of the borehole water levels acted in concert during the speed-up (days 270-276) and are therefore representative of the basal water pressure on the length scales of both tens of meters and kilometers. Such widespread connectivity between boreholes is rare and is observed at only one other time: during the spring speed-up (Harper and others, 2005, 2007). Note that the values of the water level and the magnitude of the variations in water level vary between boreholes. These differences are likely determined by the specifics of how each borehole is connected to the subglacial hydrology system, such as whether the borehole intersects the stoss or lee side of a bedrock bump. Therefore, the water-level averages might not yield the exact magnitude of the basal pressure field, but do accurately record how the basal pressure field varies through time.

\section{Pre-speed-up}

Based on glacier motion, the period prior to the speed-up event had two distinctly different modes (Fig. 2). Early in the record (days $\sim 220-245$ ), ice velocity was $2.8 \mathrm{~cm} \mathrm{~d}^{-1}$. The diurnal variations in the average borehole water levels result from strong diurnal swings in a few boreholes while the majority showed a nearly constant water level. Large headgradients often existed between closely spaced boreholes, and water-level fluctuations were not closely correlated between boreholes (Fudge and others, 2008). Several significant warm-weather and rain events occurred during this period, but none had a discernible influence on either the pressure or velocity records.

Beginning on day 248, the ice displacement changed to a new mode of significantly slower horizontal motion of only $1.6 \mathrm{~cm} \mathrm{~d}^{-1}$. Coincident with the slow horizontal motion was downward vertical motion of roughly $30 \mathrm{~cm}$ (Fig. 2b). Later, during winter conditions (days 279-328), the horizontal velocity was a steady $2 \mathrm{~cm} \mathrm{~d}^{-1}$, and we assume, supported by calculations with Glen's flow law, that this is the deformational velocity. The unusually slow velocity during the pre-speed-up period amounts to nearly $9 \mathrm{~cm}$ of motion due to internal deformation that was offset either by a change in the stress field or by reverse motion at the bed. No significant change in the borehole water-level records occurred on day 248, although the last two boreholes experiencing diurnal water-level fluctuations stopped doing so during this period. The accumulated rainfall in the 


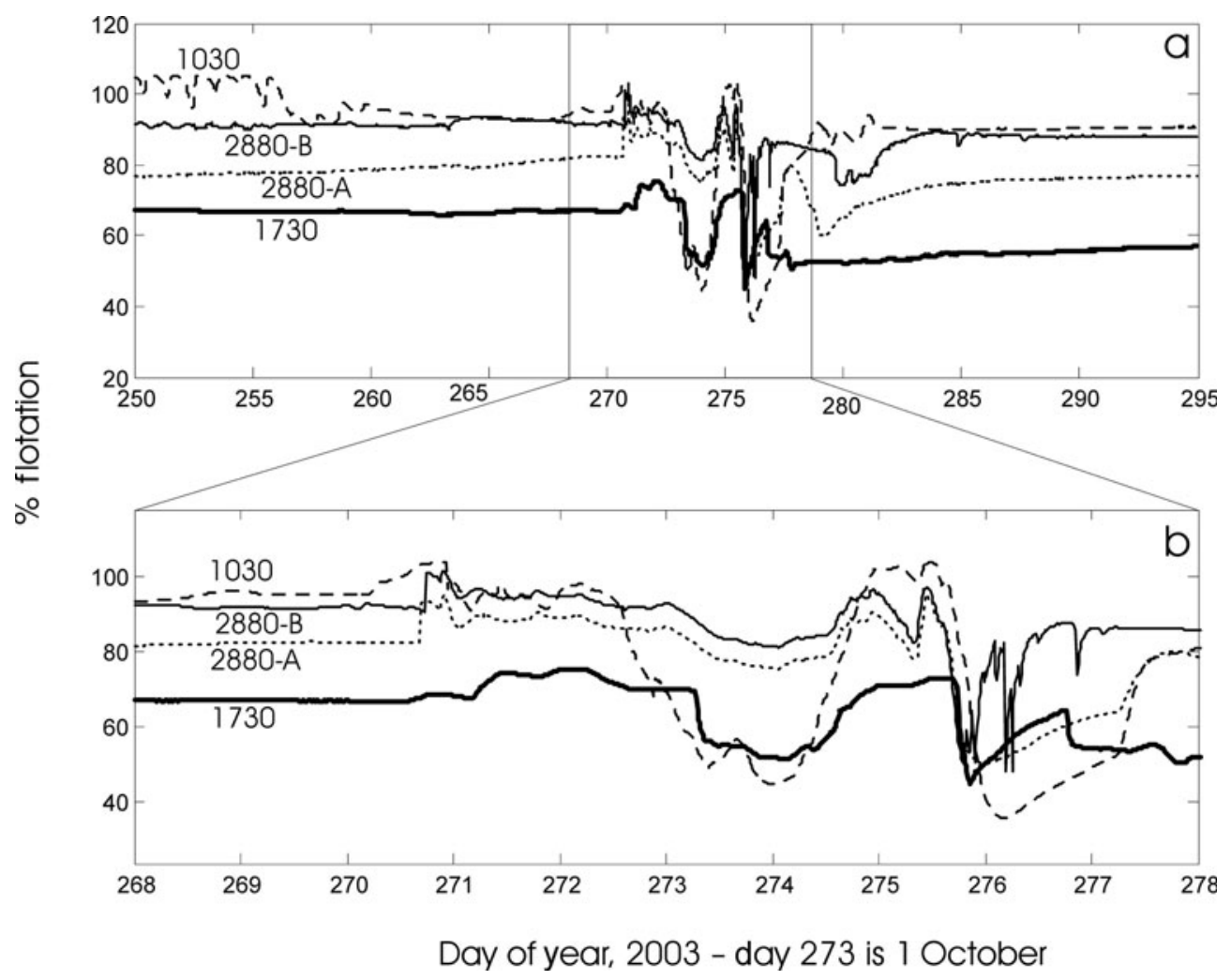

Fig. 5. Water levels from four boreholes at sites 2880 (thin solid and dotted curves), 1730 (thick curve) and 1030 (dashed curve). (a) Summer to winter transition; (b) autumn speed-up. All 15 boreholes show the same pattern of variations in water level during the autumn speed-up from day 270 to day 276 . Only during this period are the average water levels considered representative of the average basal water pressure relevant to basal sliding.

10 days after day 248 was $0.4 \mathrm{~cm}$, only one-tenth of the amount of precipitation in the preceding 10 days. The temperature dropped significantly on day 255 and conditions remained cold and dry until the speed-up.

\section{Speed-up (days 270-278)}

A sliding acceleration began gradually on day 271 . Figure 3 shows details of the horizontal positions, basal pressure and meteorological conditions during the speed-up event. The error bars on the horizontal positions represent the $95 \%$ confidence interval $(\mathrm{Cl})$. Based on the positional record, we partition the speed-up event into phase I (270.7-273.9) and phase II (273.9-278). During the first phase, rapid sliding lasted for $\sim 36$ hours (271.1-272.6) and had a gradually increasing rate of motion. During the second phase, rapid sliding occurred over $\sim 16$ hours (273.9-274.6) before leveling off. The second phase also included a short-duration reversal in the direction of motion at day 275.6. In fact, both phases ended with motion directed up-valley. Reverse motion has been observed infrequently on a number of glaciers (Willis, 1995) and recently studied in considerable detail at Gornergletscher, Switzerland (Sugiyama and others, 2007). We address its implications in the discussion.

We present the magnitude of reverse motion as the most likely value and include the range of values with a $95 \% \mathrm{Cl}$ in parentheses. The reverse motion at the end of phase I was $15 \mathrm{~cm}(4-22 \mathrm{~cm})$, during phase II it was $21 \mathrm{~cm} \mathrm{(8-}$ $34 \mathrm{~cm})$ and at the end of phase II it was $21 \mathrm{~cm}(11-31 \mathrm{~cm})$; the durations were 16,8 and 28 hours, respectively. We feel that the reverse motion at the end of both phases of the speed-up is robust because there are multiple measurements recording the progression of reverse motion. The reverse motion from 275.3 to 275.6 has a short duration (two measurements), but we find no reason to believe these positions less than the others.

The measurements of surface raising and lowering are limited by the large errors associated with the vertical positions. Uplift of $38 \mathrm{~cm}(9-74 \mathrm{~cm})$ occurred at the start of phase I (270.9-272.3), which roughly corresponds to the period of rapid sliding. Whether uplift occurred during the rapid sliding of phase II cannot be determined, but total accumulated downward displacement, after the phase I uplift until the end of phase II (272.3-277), was $62 \mathrm{~cm}$ (26$98 \mathrm{~cm})$. Specifics of the vertical motion during the individual episodes of reverse horizontal motion cannot be determined, as the errors allow anywhere from $\sim 20 \mathrm{~cm}$ of upward to $\sim 50 \mathrm{~cm}$ of downward displacement (Fig. $4 \mathrm{~b}$ ).

The local and regional water-pressure records behaved similarly during the entire speed-up period. The higher pressures during both phases of the speed-up occurred when temperatures were high and/or rainfall was occurring, and the pressure troughs coincided with reduced temperature and rainfall. Both regional and local water pressures dropped at the end of phase I, with a greater drop in regional pressure to just under $70 \%$ of flotation pressure. During phase II, the pressure showed irregular peaks and then a large drop that reduced water pressure along the glacier to less than $65 \%$ of flotation pressure.

\section{Post-speed-up (days 278-287)}

After day 277, the glacier returned to steady motion and no other rapid-motion events occurred throughout the remainder of autumn. The temperature returned to near freezing and no rainfall was recorded, implying that the precipitation 
had turned to snow. The boreholes no longer experienced synchronous variations in water level.

\section{DISCUSSION AND CONCLUSION}

\section{Water pressure and sliding speed}

Our dataset provides an opportunity to compare surface velocity before, during and after a significant speed-up event with both locally averaged (tens of meters) and regionally averaged (several kilometers) measurements of borehole water levels. The first significant finding is that rapid sliding occurred only when the borehole water levels had similar fluctuations, implying a widespread connectivity of the subglacial hydrology system. During this period (days 270276), the borehole water levels are representative of an average basal water pressure. At first inspection, the relationship between sliding speed and basal water pressure (Fig. 3a and b) shows close association. The complex multiphase speed-up with interludes of slow or reverse motion has associated pressure increases or decreases. During this event, the pressure is substantially more related to velocity than during the reoccurring ten-fold increase in speed we observe at Bench Glacier during the onset of spring melt conditions (Harper and others, 2007). In spring, the rapid sliding occurs while the basal pressure either shows no change or decreases slightly.

Closer inspection of the data, however, reveals that the relationship between pressure and velocity is complex, with pressure events sometimes leading and sometimes lagging velocity events. Several complications in particular stand out.

\section{Onset of rapid sliding:}

Phase I: A pressure increase preceded the velocity increase by $4-8$ hours.

Phase II: The start of rapid motion coincided with increasing pressure.

\section{Sustained rapid sliding:}

Phase I: Occurred while the pressure was steady and elevated (above pre-speed-up levels).

Phase II: Occurred while the pressure was increasing but low (below pre-speed-up levels).

3. End of rapid sliding:

Phase I: Occurred 4-8 hours after the pressure began dropping.

Phase II: Occurred as the pressure continued to rise for 8-12 hours.

\section{Reverse motion:}

End of phase I: Was concurrent with dropping pressure.

During phase II (275.6): Began about 8 hours after a dip in pressure.

End of phase II: Occurred while water levels were recovering from low values.

During the first phase of the speed-up, the water-pressure/ sliding relationship appears sensitive to a critical pressure predicted by theory (Iken, 1981; Truffer and Iken, 1998). A preliminary pressure spike initiated sliding, which continued while the pressure remained elevated. However, the rapid sliding of phase II did not correspond to the pressure attaining a critical value because the pressure continued to increase after the sliding had stopped. During the two phases of the speed-up, the sliding speed was not consistently linked to increasing, decreasing or a critical water pressure. This is not a unique finding, as Hanson and others (1998) observed - at Storglaciären, Sweden - that velocity both preceded and lagged pressure changes. Hence, high or increasing water pressure may have been necessary for the rapid sliding, but was not sufficient.

Basal water storage is another key variable that influences glacier sliding (e.g. Iken and others, 1983; Meier and others, 1994; Vieli and others, 2004). Water storage can be estimated by analyzing bed separation from measurements of surface uplift (e.g. Howat and others, 2008) and by calculating meltwater input and outflow (e.g. Bartholomaus and others, 2008). The surface uplift during the rapid sliding in phase I (270.9-272.3) suggests that bed separation and water storage are important during the autumn speed-up. However, the large errors in the vertical positions and the inability to constrain vertical strain with only a single measurement of velocity prevent a detailed analysis of bed separation here. With no record of the outlet stream discharge, we cannot estimate the water storage through the difference of inputs and outputs. Further, the borehole water-level records cannot straightforwardly be used to infer water storage, as Harper and others (2007) showed that bed separation occurred without a corresponding increase in borehole water levels.

Synchronous variations of the basal pressure field occurred at only one other time during the year: the annual spring speed-up (Harper and others, 2005, 2007). The synchronous behavior between 15 boreholes spaced kilometers apart implies that a large area of the basal drainage system was interconnected and had high transmissivity. A large amount of water at the bed promotes basal water connectivity, but connectivity is also promoted by enhanced sliding, which opens cavities at the bed. Connectivity in the spring commenced after an initial displacement of the ice (Harper and others, 2007). Due to the compressed timing of the autumn event and fewer borehole measurements, the exact timing of the onset of connectivity relative to ice displacement is less clear during the autumn speed-up. Nevertheless, rapid sliding at Bench Glacier occurred only during periods of widespread connectivity of the basal pressure field. This suggests that basal connectivity is a key component of rapid sliding for Bench Glacier, and might also be critical for other glaciers.

\section{Basal cavity dynamics}

High melt and rainfall conditions similar to those observed during the autumn speed-up occurred earlier in the summer (days 215-225), yet no increase in motion was observed. A likely explanation is that the capacity of the drainage system was greater during summer and surface water input was routed through efficient basal conduits. The lack of water input during the 2 week period of cold and dry conditions (with a lowering solar angle) that preceded the autumn speed-up likely reduced the capacity of the drainage system. Indeed, the downward surface motion (and associated reduced horizontal motion) may be the result of an efficient subglacial drainage network deteriorating into an inefficient one. The large increase in water input caused by the warm, wet weather beginning on day 270 might then have 
overwhelmed the inefficient drainage network. The synchronous behavior of all 15 boreholes along nearly $2 \mathrm{~km}$ of the ablation area indicates that water was forced into a widespread and highly transmissive configuration, perhaps with a feedback from ice displacement. This was likely a system of very well-linked cavities.

The reverse motion at the surface may also be the result of subglacial cavity dynamics. The repeated association of the reverse motion with shutdown of rapid sliding may imply a loss of water storage in cavities if the magnitude of surface elevation loss can explain the $15-21 \mathrm{~cm}$ of horizontal reverse motion observed. With a bed slope at site 2880 of approximately 0.15 , and assuming the water exerted a force normal to the bed, $1 \mathrm{~m}$ of elevation loss would be required to produce $15 \mathrm{~cm}$ of horizontal (backwards) motion. However, the water-ice contact in basal cavities is not necessarily parallel to the mean bed slope. Iken (1981) showed that cavities on an idealized sinusoidal bed might occupy the space between the next peak of the sine wave and the next inflection point, which effectively steepens the water-ice contact. As the wavelength for a given amplitude of the sine wave decreases, or the cavity becomes more steplike, the slope of the water-ice contact steepens. A two- to three-fold increase in effective slope from the mean slope is plausible. At slopes of 0.3 and 0.45 , we find that the downward surface motion required to achieve $15 \mathrm{~cm}$ of horizontal (backwards) motion is 50 and $33 \mathrm{~cm}$, respectively.

Although large errors in the vertical GPS measurements preclude a detailed analysis of elevation changes associated with the reverse motion, they do show downward surface motion of $62 \mathrm{~cm}(26-98 \mathrm{~cm})$ from day 272 to day 277 (Fig. 4b). Approximately $15 \mathrm{~cm}$ of lowering is due to normal down-valley motion, so $47 \mathrm{~cm}(12-83 \mathrm{~cm})$ can be attributed to a loss of bed separation if no other factors affected the vertical position. This is similar to the $33-50 \mathrm{~cm}$, computed above, that would be necessary to explain $15 \mathrm{~cm}$ of reverse motion. This analysis shows only that the rapid drainage of water from cavities is a plausible mechanism for a significant amount of the reverse motion; it does not consider individual events (because of high measurement errors) or exclude other mechanisms. In fact, it is unlikely that all of the surface lowering is the result of changes at the bed because vertical strain is an important component of surface uplift measurements (e.g. Gudmundsson, 2002). Further, if the reverse motion occurred at the large end of our measured ranges, or the downward motion at the small end, then drainage of basal water can explain only a fraction of the reverse motion.

Elastic deformation and subglacial sediment deformation were proposed as other mechanisms for reverse motion by Sugiyama and others (2007). As Bench Glacier is underlain by little till, we can eliminate subglacial sediment deformation as a possibility. A detailed estimate of the elastic deformation potentially contributing to the horizontal reverse motion is difficult because we cannot calculate the longitudinal stress from a point-velocity measurement. However, assuming standard flow-law values from Paterson (1994), and that the highest velocity observed $\left(\sim 1 \mathrm{~m} \mathrm{~d}^{-1}\right)$ occurred when another part of the glacier $1 \mathrm{~km}$ away did not move, gives a longitudinal stress of $\sim 10^{5} \mathrm{~Pa}$. Using $8.3 \times 10^{9} \mathrm{~Pa}$ for Young's modulus for ice (Hooke, 1998), we calculate that a stress of this magnitude could produce $\sim 0.01 \mathrm{~m}$ of instantaneous elastic strain. The observed relaxation times of $8-28$ hours imply that no more than
$15 \%(\sim 0.002 \mathrm{~m})$ of the strain can be recovered elastically (Sugiyama and others, 2007, equation 1). Therefore, we find it difficult to attribute any significant amount of reverse motion to elastic deformation.

The above calculations suggest that reverse motion smaller than $15 \mathrm{~cm}$ can be plausibly explained by rapidly draining cavities and a loss of bed separation, implying that either the observed reverse motion was not at the high end of our possible range or other unaccounted-for processes were at play. If a loss of bed separation was the dominant mechanism of reverse motion, we note that only the reverse motion at the end of phase I occurred during declining water pressure. The reverse motion at the end of phase II coincided with increasing water levels, although variations were no longer synchronous between boreholes, and cavities might have become isolated. These results illustrate that reversemotion events provide a new perspective on subglacial cavity dynamics during rapid sliding and highlight the need for more observations.

\section{ACKNOWLEDGEMENTS}

We thank the scientific editor, T. Murray, and two reviewers, D. Benn and T. Bartholomaus, for helpful comments that improved the manuscript. We also thank the many people who conducted fieldwork on Bench Glacier. The input of the glaciology group at University of Washington, particularly D. Power and A. Rasmussen, was of great help.

\section{REFERENCES}

Anderson, R.S. and 6 others. 2004. Strong feedback between hydrology and sliding of a small alpine glacier. J. Geophys. Res., 109(F3), FO3005. (10.1029/2004JF000120.)

Bartholomaus, T.C., R.S. Anderson and S.P. Anderson. 2008. Response of glacier basal motion to transient water storage. Nature Geosci., 1(1), 33-37.

Bradford, J.H. and J.T. Harper. 2005. Wave field migration as a tool for estimating spatially continuous radar velocity and water content in glaciers. Geophys. Res. Lett., 32(8), L08502. (10.1029/2004GL021770.)

Fountain, A.G. 1994. Borehole water-level variations and implications for the subglacial hydraulics of South Cascade Glacier, Washington State, U.S.A. J. Glaciol., 40(135), 293-304.

Fountain, A.G. and J.S. Walder. 1998. Water flow through temperate glaciers. Rev. Geophys., 36(3), 299-328.

Fowler, A.C. 1987. Sliding with cavity formation. J. Glaciol., 33(115), 255-267.

Fudge, T.J., J.T. Harper, N.F. Humphrey and W.T. Pfeffer. 2005. Diurnal water-pressure fluctuations: timing and pattern of termination below Bench Glacier, Alaska, USA. Ann. Glaciol., 40, 102-106.

Fudge, T.J., N.F. Humphrey, J.T. Harper and W.T. Pfeffer. 2008. Diurnal fluctuations in borehole water levels: configuration of the drainage system beneath Bench Glacier, Alaska, USA. J. Glaciol., 54(185), 297-306.

Gordon, S., M. Sharp, B. Hubbard, C. Smart, B. Ketterling and I. Willis. 1998. Seasonal reorganization of subglacial drainage inferred from measurements in boreholes. Hydrol. Process., 12(1), 105-133.

Gudmundsson, G.H. 2002. Observations of a reversal in vertical and horizontal strain-rate regime during a motion event on Unteraargletscher, Bernese Alps, Switzerland. J. Glaciol., 48(163), 566-574.

Hanson, B., R.LeB. Hooke and E.M. Grace, Jr. 1998. Short-term velocity and water-pressure variations down-glacier from a riegel, Storglaciären, Sweden. J. Glaciol., 44(147), 359-367. 
Harper, J.T., N.F. Humphrey, W.T. Pfeffer, S. Huzurbazar, D.B. Bahr and B.C. Welch. 2001. Spatial variability in the flow of a valley glacier: deformation of a large array of boreholes. J. Geophys. Res., 106(B5), 8547-8562.

Harper, J.T., N.F. Humphrey and M.C. Greenwood. 2002. Basal conditions and glacier motion during the winter/spring transition, Worthington Glacier, Alaska, U.S.A. J. Glaciol., 48(160), 42-50.

Harper, J.T., N.F. Humphrey, W.T. Pfeffer, T. Fudge and S. O'Neel. 2005. Evolution of subglacial water pressure along a glacier's length. Ann. Glaciol., 40, 31-36.

Harper, J.T., N.F. Humphrey, W.T. Pfeffer and B. Lazar. 2007. Two modes of accelerated glacier sliding related to water. Geophys. Res. Lett., 34(12), L12503. (10.1029/2007/GL030233.)

Heroux, P. and J. Kouba. 2001. GPS precise point positioning using IGS orbit products. Phys. Chem. Earth, 26(6-8), 573-578.

Hooke, R.LeB. 1998. Principles of glacier mechanics. Upper Saddle River, NJ, Prentice Hall.

Howat, I.M., S. Tulaczyk, E. Waddington and H. Bjornsson. 2008. Dynamic controls on glacier basal motion inferred from surface ice motion. J. Geophys Res., 113(F3).

Iken, A. 1981. The effect of the subglacial water pressure on the sliding velocity of a glacier in an idealized numerical model. J. Glaciol., 27(97), 407-421.

Iken, A. and M. Truffer. 1997. The relationship between subglacial water pressure and velocity of Findelengletscher, Switzerland, during its advance and retreat. J. Glaciol., 43(144), 328-338.

Iken, A., H. Röthlisberger, A. Flotron and W. Haeberli. 1983. The uplift of Unteraargletscher at the beginning of the melt season a consequence of water storage at the bed? J. Glaciol., 29(101), 28-47.

Jansson, P. 1995. Water pressure and basal sliding on Storglaciären, northern Sweden. J. Glaciol., 41(138), 232-240.

Joughin, I., S.B. Das, M.A. King, B.E. Smith, I.M. Howat and T. Moon. 2008. Seasonal speedup along the western flank of the Greenland Ice Sheet. Science, 320(5877), 781-783.

Kamb, B., H. Engelhardt, M.A. Fahnestock, N. Humphrey, M. Meier and D. Stone. 1994. Mechanical and hydrologic basis for the rapid motion of a large tidewater glacier. 2. Interpretation. J. Geophys. Res., 99(B8), 15,231-15,244.
King, M. 2004. Rigorous GPS data-processing strategies for glaciological applications. J. Glaciol., 50(171), 601-607.

Lliboutry, L. 1968. General theory of subglacial cavitation and sliding of temperate glaciers. J. Glaciol., 7(49), 21-58.

Magnússon, E., H. Rott, H. Björnsson and F. Pálsson. 2007. The impact of jökulhlaups on basal sliding observed by SAR interferometry on Vatnajökull, Iceland. J. Glaciol., 53(181), 232-240.

Mair, D., P. Nienow, I. Willis and M. Sharp. 2001. Spatial patterns of glacier motion during a high-velocity event: Haut Glacier d'Arolla, Switzerland. J. Glaciol., 47(156), 9-20.

Meier, M. and 9 others. 1994. Mechanical and hydrologic basis for the rapid motion of a large tidewater glacier. 1. Observations. J. Geophys. Res., 99(B8), 15,219-15,229.

O'Neel, S., K.A. Echelmeyer and R.J. Motyka. 2001. Short-term flow dynamics of a retreating tidewater glacier: LeConte Glacier, Alaska, U.S.A. J. Glaciol., 47(159), 567-578.

Paterson, W.S.B. 1994. The physics of glaciers. Third edition. Oxford, Elsevier

Röthlisberger, H. 1972. Water pressure in intra- and subglacial channels. J. Glaciol., 11(62), 177-203.

Schoof, C. 2005. The effect of cavitation on glacier sliding. Proc. $R$. Soc. London, Ser. A, 461(2055), 609-627.

Sugiyama, S., A. Bauder, P. Weiss and M. Funk. 2007. Reversal of ice motion during the outburst of a glacier-dammed lake on Gornergletscher, Switzerland. J. Glaciol., 53(181), 172-180.

Truffer, M. and A. Iken. 1998. The sliding velocity over a sinusoidal bed at high water pressure. J. Glaciol., 44(147), 379-382.

Truffer, M., W.D. Harrison and R.S. March. 2005. Correspondence. Record negative glacier balances and low velocities during the 2004 heatwave in Alaska, USA: implications for the interpretation of observations by Zwally and others in Greenland. J. Glaciol., 51(175), 663-664.

Vieli, A., J. Jania, H. Blatter and M. Funk. 2004. Short-term velocity variations on Hansbreen, a tidewater glacier in Spitsbergen. J. Glaciol., 50(170), 389-398.

Willis, I.C. 1995. Intra-annual variations in glacier motion: a review. Progr. Phys. Geogr., 19(1), 61-106.

Zwally, H.J., W. Abdalati, T. Herring, K. Larson, J. Saba and K. Steffen. 2002. Surface melt-induced acceleration of Greenland ice-sheet flow. Science, 297(5579), 218-222. 